\title{
Análise seminal e pós-seminal do pau-pretinho em diferentes substratos, testando resíduos na produção de mudas
}

O Cenostigma tocantinum Ducke é uma espécie distribuída geograficamente no norte do Brasil, objetivou-se verificar a eficiência de diferentes resíduos agroflorestais na produção de mudas da espécie, sob a ação de diferentes substratos. O experimento foi conduzido em viveiro da Universidade Federal Rural da Amazônia, localizado em Belém do Pará. Utilizou-se delineamento inteiramente casualizado, totalizando 320 sementes, correspondendo a quatro tratamentos ( $T$ ), com 80 sementes cada, formado de oito repetições de 10 sementes, onde (T0) terra preta; (T1) terra preta + substrato comercial em proporção 2:1; (T2) terra preta + resíduo castanha em proporção 2:1; (T3) terra preta + resíduo caroço açaí em proporção 2:1. As sementes iniciaram a germinação aos 3 dias após a data de semeadura. Os resultados encontrados no presente estudo apontam que todos os tratamentos foram eficientes, porém, nos paramentos avaliados a média do diâmetro do colo teve destaque o (T0), alturas das plantas (T1) e no número de folhas o (T2) teve maior influência. Foi comprovado que a incorporação desses resíduos agroflorestais nos substratos, pode diminuir o uso da terra preta e obter os mesmos resultados quanto aos aspectos de vigor da muda.

Palavras-chave: Produção de mudas; Germinação; Casca de castanha; Caroço de açaí.

\section{Seminal and post-seminal analysis of peanut duct in different substrates, testing residues in the production of changes}

Cenostigma tocantinum Ducke is a species of native origin, distributed geographically in the north of Brazil, the present work had as objective to verify the efficiency of different agroforestry residues in the production of seedlings of the species, under the action of different substrates. The experiment was conducted in one of the nurseries of the Federal Rural University of Amazonia, located in Belém do Pará. A completely randomized design was used, totaling 320 seeds, corresponding to four treatments (T), with 80 seeds each, consisting of eight replicates of 10 seeds, where (T0) black soil; (T1) black soil + commercial substrate in 2: 1 ratio; (T2) black soil + brown residue in 2: 1 ratio; (T3) black soil + açaí stone residue in 2: 1 ratio. The seeds began germination at 3 days after sowing date. The results found in the present study indicate that all the treatments were efficient, but in the evaluated parisons the average of the diameter of the neck was highlighted (TO), plant height (T1) and leaf number (T2). It has been proven that the incorporation of these agroforestry residues into the substrates can decrease the use of black soil and obtain the same results regarding the vigor aspects of the seedlings.

Keywords: Production of seedlings; Germination; Chestnut bark; Açaí seed.

Topic: Ciências Florestais

Reviewed anonymously in the process of blind peer.
Received: 09/03/2020

Approved: 21/06/2020
Jéssica Costa dos Santos (iD

Universidade Federal Rural da Amazônia, Brasil

http://lattes.cnpq.br/8061391874732225

http://orcid.org/0000-0002-4424-1821

jessicasantos.ufra@gmail.com

Juliana Wanessa Costa Barros (iD

Universidade Federal Rural da Amazônia, Brasil

http://lattes.cnpq.br/3641245937304377

http://orcid.org/0000-0002-2955-6104

julianabarros.engflorestal@gmail.com

\section{Flavia Giseli Galvão Marinho}

Universidade Federal Rural da Amazônia, Brasil

http://lattes.cnpq.br/4983413363361657

gisellimarinho@hotmail.com

\author{
Fernanda Yukari de Souza Sakuma (iD) \\ Universidade Federal Rural da Amazônia, Brasil \\ http://lattes.cnpq.br/4305525882492304 \\ http://orcid.org/0000-0003-4107-544X \\ fernandasakuma18@gmail.com \\ Thais de Nazaré Oliveira Novais \\ Universidade Federal Rural da Amazônia, Brasil \\ http://lattes.cnpq.br/0755520013937924 \\ http://orcid.org/0000-0003-3890-3881 \\ thaisnovais4@gmail.com \\ Francimary da Silva Carneiro \\ Universidade Federal Rural da Amazônia, Brasil \\ http://lattes.cnpq.br/8657235544233319 \\ http://orcid.org/0000-0002-1693-8779 \\ francimarycarneiro@gmail.com
}

Referencing this:

SANTOS, J. C.; BARROS, J. W. C.; MARINHO, F. G. G.; SAKUMA, F. Y. S.; NOVAIS, T. N. O.; CANEIRO, F. S.. Análise seminal e pós-seminal do pau-pretinho em diferentes substratos, testando resíduos na produção de mudas. Natural Resources, v.10, n.2, p.38-43, 2020. DOI: http://doi.org/10.6008/CBPC2237-9290.2020.002.0005 


\section{INTRODUÇÃO}

A espécie Cenostigma tocantinum Ducke pertence à família Fabaceae, é conhecido popularmente como pau-pretinho, mangirimbá, inharé e entre outros. A espécie tem um forte potencial para a arborização urbana. O autor Sousa et al. (2008) descreve que a espécie floresce o ano todo, com maior frequência no período de menor precipitação. Seu tronco chama a atenção, pela sua tortuosidade e presença de caneluras longitudinais. Seu potencial também está ligado a ser uma árvore com sistema radicular pouco agressivo e tolerar solos ácidos.

Para a produção de mudas seja qualquer a finalidade e espécie, faz necessários procedimentos apropriados e a adesão de padrões técnicos na composição de substratos, que resultará na melhor qualidade das mudas, também na formação de plantas mais vigorosas, uniformes, mais fortes para o replantio, ou seja, mais resistentes às condições ambientais quando forem para o campo (CALDEIRA et al., 2012).

A Lei de Resíduos Sólidos (lei $n^{\circ} 12.305$ de 2010) determina que a responsabilidade do descarte seja do próprio produtor/empresário. Os resíduos agroflorestais em grande maioria não são aproveitados e geralmente empilhados e jogados como lixo pelo produtor. Em Belém, o descarte dos resíduos do açaí é um problema. Como a responsabilidade pela destinação dos caroços é dos próprios batedores, na maioria das vezes é realizado nos canais, cursos d'água, causando sérios problemas de escoamento, além de contribuir para a atração de insetos e outros bichos. Causando graves consequências para a para a saúde e bem-estar da população.

O autor Soares et al. (2014) reconhece em seu trabalho que pesquisadores do mundo inteiro, durante décadas buscam e desenvolvem pesquisas por novas alternativas de materiais que possam compor substratos para a produção de mudas. Os quais esses materiais possam ser economicamente e ambientalmente corretos. A adição de materiais orgânicos na produção de mudas em viveiros florestais é comum, com o objetivo de adicionar e aprimorar os atributos em geral dos substratos. Mas de forma geral, as composições do substrato são pobres em nutrientes primordiais para o crescimento da planta nessa fase inicial (DELARMELINA et al., 2014).

Diante desse cenário, se faz necessário buscar novos componentes viáveis, que possam participar na formulação do substrato. A utilização de resíduos como da castanha e do açaí, diminui o custo e o impacto ambiental. Este trabalho objetivou verificar a eficiência de diferentes resíduos agroflorestais na produção de mudas da espécie importante para a arborização urbana, chamada de Cenostigma tocatinum, vulgarmente conhecida como pau-pretinho.

\section{METODOLOGIA}

O local de implantação do experimento foi no viveiro do Instituto de Ciências Agrarias, da Universidade Federal Rural da Amazônia (UFRA), campus Belém/PA. A preparação do trabalho é dividida em três fases: coleta de sementes, preparo do substrato e implantação do experimento. A coleta das sementes da espécie Cenostigma tocantinum Ducke foi realizada na UFRA, campus Belém/PA. Utilizando-se a 
ferramenta podão foram coletados ramos contendo os frutos, do tipo vagem, que protegem as sementes. Foi feito o beneficiamento das mesmas e a biometria da vagem e das sementes, sendo medidos com o auxílio de um paquímetro digital.

O preparo dos substratos teve início com a reunião dos quatro elementos que os compõe, sendo o caroço de açaí e casca de castanha, secos ao sol por três dias e triturados, os elementos tiveram procedência da Universidade Federal Rural da Amazônia. O delineamento experimental foi o inteiramente casualizado com oito repetições, cada uma com dez indivíduos, totalizando trezentos e oitenta plantas. Foram usadas três composições de substrato (terra preta + Substrato comercial-T1 (2:1); terra preta + c de casca de castanha-T2 (2:1); terra preta + caroço de açaí-T3 (2:1)) e a terra preta como testemunha-T0. Como parâmetros de avaliação foram mensurados altura de planta $(\mathrm{cm})$ com régua, diâmetro de caule abaixo do coleto $(\mathrm{mm})$ com paquímetro digital e conferido o número de folhas por planta.

A manutenção e acompanhamento diário do experimento foram da seguinte maneira, regado todos os dias nos horários a partir de 16 horas, sendo retiradas as plantas invasoras para não influenciar no desenvolvimento das mudas e a verificação da germinação, sendo nesse caso considerada germinação a emergência do cotilédone. Sendo totalizado o período do experimento 37 dias. As médias foram comparadas pelo teste de Tukey a 5\% pelo Software Minitab 17, e os dados foram submetidos à análise de correlação entre todas as variáveis pelo software Microsoft Excel 2013.

\section{RESULTADOS E DISCURSÃO}

Foram mensurados comprimento, largura e espessura de 90 vagens de Cenostigma tocantinum Ducke, estes apresentaram média em comprimento de $11,5 \mathrm{~cm}$, mínimo de 7,6 cm e máximo de $14,4 \mathrm{~cm} ; \mathrm{Em}$ largura apresentaram média de 2,09 cm e mínimo 1,52 cm e máximo 2,29cm; Espessura média de 0,81 cm, mínimo 0,68 cm e máximo de 0,84 cm, valores aproximados foram encontrados por Silva (2007), onde o comprimento médio apresentaram cerca de $8,9 \mathrm{~cm}$, mínimo de 6,5 cm e máximo $11,6 \mathrm{~cm}$; para largura foram encontrados média de 2,2 cm, 1,6 cm mínimo e máximo de 2,7 cm; espessura média de 0,5 cm, mínimo de $0,3 \mathrm{~cm}$ e máximo de $0,8 \mathrm{~cm}$.

Também foram mensurados dimensões de 200 sementes, onde apresentaram comprimento médio de 1,49 cm, mínimo 1,19 cm de e máximo 1,92 cm; e em largura apresentaram média de 1,34 cm, mínimo 1,02 cm e máximo de 1,72 cm. Segundo Silva (2007) em analise, as dimensões da semente do Cenostigma tocantinum apresentaram média de 1,5 cm e mínimo $1,2 \mathrm{~cm}$ e máximo $1,9 \mathrm{~cm}$; e largura média de $1,4 \mathrm{~cm}$, mínimo 1,0 cm e máximo $1,8 \mathrm{~cm}$ o que pode se observar aproximação entre os dados biométricos da semente da espécie estudada.

As sementes começaram a germinar três dias após a semeadura, prolongando-se por sete dias, como pode-se observar na figura 1. Nos diferentes tratamentos os valores de germinação positiva e negativa não tiveram diferença simbólica, podendo ser observado na tabela 1. 0 tratamento que mostrou um diferencial foi o T2, com uma média de 83,75 , um pouco maior que os outros tratamentos. Não houve correlação 
significativa entre as variáveis medidas, entre altura da planta e o diâmetro do colo o coeficiente de correlação (R) foi de $-3 \%$, número de folhas e diâmetro do colo $(R=-43 \%)$ e número de folhas com altura da planta de ( $R=31 \%)$. Devido ao baixo grau de associação entre as variáveis, não se prosseguiu para o estudo de regressão.

Tabela 1: Avaliação de germinação de sementes de Cenostigma tocantinum submetidas a diferentes substratos.

\begin{tabular}{|c|c|c|c|c|c|c|}
\hline \multirow{2}{*}{\multicolumn{2}{|c|}{ - Tratamentos }} & \multicolumn{2}{|c|}{ Germinação } & \multirow{2}{*}{ Total } & \multirow{2}{*}{$\begin{array}{l}\text { Percentual de } \\
\text { Germinação (\%) }\end{array}$} & \multirow{2}{*}{ IVG \% } \\
\hline & & Positiva & Negativa & & & \\
\hline TO & & 68 & 12 & 80 & 85 & 9,7143 \\
\hline T1 & & 68 & 12 & 80 & 85 & 9,7143 \\
\hline $\mathrm{T} 2$ & & 69 & 11 & 80 & 86,25 & 9,8571 \\
\hline T3 & & 67 & 13 & 80 & 83,75 & 9,5714 \\
\hline Total & & 272 & 48 & 320 & - & - \\
\hline
\end{tabular}

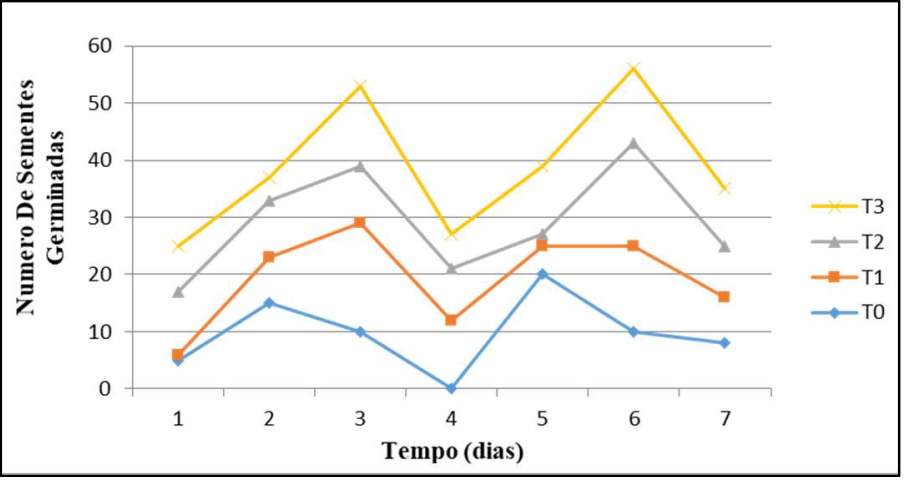

Figura 1: Germinação de sementes de Cenostigma tocantinum submetidas a diferentes substratos (dados acumulados).

Não houve diferença estatística significativa entre as variáveis e os tratamentos, todos os tratamentos mostraram-se eficientes no desenvolvimento das plantas. No entanto, mesmo havendo diferenças mínimas no crescimento do diâmetro do coleto, a testemunha (TO), apresentou uma maior média; enquanto o crescimento em altura da planta, o tratamento com terra preta + substrato comercial (T1), apresentou o maior resultado; e para o número de folha foi o tratamento T2 (tabela 1).

Soares et al. (2014), em seu trabalho concluiu que a casca de castanha apresentou os maiores valores na maioria das características avaliadas, como os teores totais de nitrogênio (N), Ca, K, P, Mg, Cu, Fe, Mn, Zn, propriedades químicas que ajudam no potencial deste material como substrato. Martins et al. (2014) testou a utilização de diferentes substratos comerciais em seu trabalho, tendo como o melhor resultado quanto aos valores de crescimento em altura e diâmetro do caule, a utilização do substrato Germina plant, o mesmo utilizado neste presente trabalho.

Outros trabalhos como de Elacher (2014), Maranho et al. (2013), Soares et al. (2014), não tiveram respostas significativas e promissoras com a utilização do caroço ou resíduos de açaí na produção dos substratos, neste trabalho o substrato do T3, foi o que apresentou a menor média de todas as variáveis biométricas (tabela 2). No entanto, no trabalho de Farinas (2009), concluiu-se que o caroço do açaí se apresentou promissor quanto a sua utilização como fonte de biomassa para produção de enzimas celulases e hemicelulases, mas que estudos complementares para um ajuste dos parâmetros operacionais do processo fermentativo estariam sendo realizados visando a otimização da produção destas enzimas, de forma a 
contribuir para a cadeia produtiva de biocombustíveis e valoração da cadeia do açaí.

Tabela 2: Valores médios de crescimento em diâmetro do colo (DC), em altura da planta (AP) e número de folhas (NF) das mudas de pau-preto (Cenostigma tocantinum Duck.), submetidas a diferentes substratos.

\begin{tabular}{llll}
\hline TRATAMENTOS & DC & AP & $\mathrm{NF}$ \\
\hline T0 (TESTEMUNHA) & $2,2185 \mathrm{~A}$ & $12,153 \mathrm{~A}$ & $3,716 \mathrm{~A}$ \\
T1 (TERRA PRETA+ SUBSTRATO COMERCIAL) & $2,1571 \mathrm{~A}$ & $12,513 \mathrm{~A}$ & $3,810 \mathrm{~A}$ \\
T2 (TERRA+CASTANHA) & $2,0933 \mathrm{~A}$ & $12,350 \mathrm{~A}$ & $4,0172 \mathrm{~A}$ \\
T3 (TERRA PRETA+AÇAÍ) & $2,0552 \mathrm{~A}$ & $12,106 \mathrm{~A}$ & $3,700 \mathrm{~A}$ \\
\hline
\end{tabular}

1 Médias seguidas pela mesma letra, nas colunas, não diferem entre si pelo critério estatístico de Tukey, a $5 \%$ de probabilidade.

Portanto, como para esse trabalho não houve diferença estatística significativa entre as variáveis e os tratamentos, e todos os tratamentos se mostraram eficientes no desenvolvimento da espécie estudada, ainda que pequena a diferença o substrato que teve umas das melhores médias comparadas, levando em consideração o menor custo econômico e menor impacto ambiental que neste trabalho seria o tratamento 2 com a composição de terra preta e casca de castanha-do-Pará.

\section{CONCLUSÕES}

A espécie Cenostigma tocantinum Ducke se comportou de forma semelhante nos diferentes tratamentos. Verificou-se que a incorporação desses resíduos no substrato, diminuiu o uso da terra preta e obtiveram-se os mesmos resultados quanto aos aspectos de vigor da muda. As taxas de germinação por tratamento não diferiram muito entre si. $\mathrm{Na}$ análise das variáveis, não houve necessidade do estudo de regressão, pois as correlações existentes foram abaixo de 50\%. A composição de substrato mais recomendada seria a do $\mathrm{T} 2$.

\section{REFERÊNCIAS}

CALDEIRA, M. V. W.; PERONI, L.; GOMES, D. R.; DELARMELINA, W. M.; TRAZZI, P. A.. Diferentes proporções de biossólido na composição de substratos para a produção de mudas de timbó (Ateleia glazioveana Baill). Scientia Forestalis, v.40, n.93, p.15-22, 2012.

DELARMELINA, W. M.; CALDEIRA M. V. W.; FARIA, J. C. T.; GONÇALVES, E. O.; ROCHA, R. L. F.. Diferentes Substratos para a Produção de Mudas de Sesbania virgata. Revista Floresta e Ambiente, v.21, n.2, p.224-233, 2014.

ELACHER, W. A.; OLIVEIRA, F. L. S. D. M. N.; QUARESMA, M. A. L.; CHRISTO, B. F.. Caroço de açaí triturado fresco na formulação de substrato para a produção de mudas de hortaliças brássicas. Enciclopédia Biosfera, Goiânia, v.10, n.18, p.2930, 2014.

FARINAS, C. S.; SANTOS, R. R. M.; NETO, V. B.; PESSOA, J. D. C.. Aproveitamento do caroço do açaí como substrato para a produção de enzimas por fermentação em estado sólido. Boletim de Pesquisa e Desenvolvimento. São Carlos: Embrapa Instrumentação Agropecuária, 2009.

MARANHO, Á. S.; PAIVA, A. V.; PAULA, S. R. P.. Crescimento inicial de espécies nativas com potencial madeireiro na Amazônia, Brasil. Revista Árvore, Viçosa, v.37, n.5, p.913-
921, 2013.

MARTINS, T. S.; SERRANO, L. A. L.; HAWERROTH, F. J., TANIGUCHI, C. A. K.; MELO, D. S.; FEITOSA, M. M.. Produção de mudas de cajueiro-anão 'CCP 76' em substratos comerciais fertilizados com adubo de liberação lenta (NPK 16-08-12). In: SEMINÁRIO BAHIANO DE SOLOS, 3. Anais. Ilhéus, 2014.

SILVA, R. L.. Fenologia em ambiente urbano, morfologia da semente e da plântula e germinação sob condições adversas de Cenostigma tocantinum Ducke. Dissertação (Mestrado em Área de concentração de ciências de Florestas Tropicais) - Instituto Nacional de Pesquisas da Amazônia, Manaus, 2007.

SOARES, I. D.; PAIVA, A. V.; MIRANDA, R. O. V.; MARANHO, Á. S.. Propriedades Físico-Químicas De Resíduos Agroflorestais Amazônicos Para Uso Como Substrato. Nativa, Sinop, v.2, n.3, p.155-161, 2014. DOI: http://doi.org/10.14583/2318-7670.v02n03a05

SOUSA, S. G. A.; MORAES, R. P.; GARCIA, L. C.. Pau-pretinho (Cenostigma tocantinum Ducke) uma espécie com potencial para arborização urbana em Manaus/AM. in: CONGRESSO BRASILEIRO DE ARBORIZAÇÃO URBANA, 12; CONSERVAÇÃO 
E EXPANSÃO DOS ESPAÇOS VERDES: UM DESAFIO AO GERENCIAMENTO URBANO: PALESTRAS, RESUMOS E
RELATOS DE EXPERIÊNCIAS. Anais. Manaus: Sociedade Brasileira de Arborização Urbana, 2008.

A CBPC - Companhia Brasileira de Produção Científica (CNPJ: 11.221.422/0001-03) detém os direitos materiais desta publicação. Os direitos referem-se à publicação do trabalho em qualquer parte do mundo, incluindo os direitos às renovações, expansões e disseminações da contribuição, bem como outros direitos subsidiários. Todos os trabalhos publicados eletronicamente poderão posteriormente ser publicados em coletâneas impressas sob coordenação da Sustenere Publishing, da Companhia Brasileira de Produção Científica e seus parceiros autorizados. Os (as) autores (as) preservam os direitos autorais, mas não têm permissão para a publicação da contribuição em outro meio, impresso ou digital, em português ou em tradução. 